\title{
Over-the-counter cough medicines in children: neither safe or efficacious?
}

Patients are encouraged to self-manage acute upper respiratory illness (URTI) and take over-the-counter treatments (OTC) to relieve symptoms rather than attend GPs or seek professional services out of hours. ${ }^{1}$ One of the most troublesome symptoms of acute URTI is cough, particularly in young children in whom nocturnal symptoms can cause considerable sleep disruption. Understandably, parents have a strong urge to relieve cough in their children with OTC cough medicines, and consumers purchase approximately 95 million of these products per year in the US alone. ${ }^{2}$ In the UK, there are approximately 24 million episodes of use of OTC cough medicines per year, with children being more likely to be exposed due to their higher frequency of URTI. ${ }^{3}$ Many different preparations are available for purchase, and the British National Formulary no longer provides a full listing, stating that 'the rationale for some is dubious'. OTC cough medicines and their combinations of active ingredients vary from simple mucolytics to other active pharmacological agents such as bronchodilators, antihistamines, and centrally-acting cough suppressants. While the use of antihistamines may relieve symptoms in cough related to allergy, there is no rationale for their inclusion in OTC cough medicines targeted at all children, other than enabling suppliers to promote them as an aid to sleep, which, given their potential for misadventure, is inappropriate.

There are growing concerns about safety and doubts about the efficacy around the use of OTC cough medicines in children. ${ }^{2,4}$ This highlights the difficulty in achieving a balance between evidence-based practice, benefits and harms of treatments, and patient self-management. This lack of evidence concerning OTC cough medicines falls into what has been referred to as the 'grey zones of clinical practice' and reflects gaps in the evidence available to guide treatment decisions. For example,
$46 \%$ of the 2500 treatments for all conditions currently covered by the evidence-based medicine resource book for clinicians, Clinical Evidence, have unknown effectiveness. ${ }^{5,6}$

Our recently updated Cochrane review of OTC cough medicines for acute cough included eight trials involving children and concludes that there is no good evidence for or against the effectiveness of OTC cough medicines in acute cough. ${ }^{7}$ The limitations of this review relate to the small number of studies in each category of cough preparations. There were conflicting results between individual randomised controlled trials with consequent uncertainty regarding the clinical importance of the findings. When the review was first published there was debate about the clinical meaning of its findings, as lack of evidence does not necessarily mean lack of effect. ${ }^{8}$ Additional concerns relate to the lack of information regarding the non-respiratory effects of these agents in infants with acute URTI. It is difficult to carry out studies in younger children, with the consequence that findings from studies carried out in adults are extrapolated to paediatric populations. ${ }^{9}$ Clinicians may wish to offer some remedy to alleviate the frequency and severity of cough even if they doubt its efficacy, but products need to be safe, particularly in young children.

Systematic reviews of randomised controlled trials of OTC cough medicines suggest that adverse effects are relatively minor and not significantly different between treatment and placebo groups. ${ }^{7}$ More serious concerns about the safety of OTC cough medicines have arisen following a review of the use of these products by the US Food and Drug Administration (FDA) after convening a meeting of an expert panel in October 2007 'to discuss a Citizen Petition submitted to the Agency regarding the safety and efficacy of cold and cough products in children especially those under the age of 6 years'. ${ }^{5}$ The FDA previously completed an internal review of observational studies assessing lifethreatening side effects and death in children younger than 6 years. This review reports 54 cases of death with decongestants and 69 with antihistamines between 1969 and 2006, with the majority of these deaths in children younger than 2 years of age. The review provides detailed analysis of the individual deaths and concludes that the deaths related to accidental exposure (22\%), intentional overdose (6\%), and medication error (16\%) with the manner of overdose undetermined in the remaining $56 \%$ of cases. ${ }^{10}$ Given the extent of use of OTC cough medicines, these adverse events are relatively rare. However, because of the lack of evidence regarding their efficacy, even these small absolute risks of adverse effects shift the benefit versus adverse risk ratio against the use of OTC cough medicines in children. In addition, anecdotal reports to us from pharmacists and material viewed on internet parenting sites have raised concerns regarding the use of OTC cough medicines as sleep aids for children with or without cough by some parents despite professional advice to the contrary. ${ }^{11}$

Consideration of the safety of OTC cough medicines highlights the need for improved evidence for drug safety in general. While randomised controlled trials may provide evidence for common side effects, rarer adverse events are unlikely to be picked up by clinical trials, and there is still a need for large scale longitudinal observational studies such as those that identified the deaths relating to OTC cough medicines in young children.

In the week that the FDA expert committee met, the manufacturers of OTC cough medicines in the US voluntarily withdrew their products for children under 2 years of age but continue to market these products for children aged over 
2 years. They now formally recommend that OTC cough and cold medicines should not be used in children under 2 years and state that they are still evaluating treatment with OTC cough medicines in older children. ${ }^{10}$

In March 2008, the Medicines and Healthcare Products Regulatory Agency (MHRA) in the UK adopted a similar position based on the expert advice of a Paediatric Medicines Advisory Group within the Commission on Human Medicines. ${ }^{12}$ As a result, OTC cough medicines for children under 2 years have been withdrawn in the UK, and the pharmaceutical industry has also voluntarily agreed to alter labelling to remove dosage instructions for children under 2 years in products still available for older children. Despite these changes in the labelling and marketing of OTC cough medicines, more could be done to make it clear to consumers that the efficacy of these products still needs to be established. ${ }^{2}$

Many health professionals working in primary care encounter children and their parents after they have spent several days using OTC cough medicines as they are suffering ongoing disruptive symptoms. These consultations provide an opportunity for patient education regarding normal cough duration. Clinicians and parents tend to overestimate how quickly children are likely to recover from acute cough, making it more likely that persistent cough will be regarded as pathological and requiring treatment. ${ }^{13}$ Recommendations about the use of OTC cough medicines are further complicated by the diversity of products available with varying risk of adverse effects. A simple solution adopted by some practitioners and now recommended by the MHRA in the UK, is to actively promote the use of simple cough syrups such as glycerol, lemon, or honey. For example a recent randomised controlled trial of honey (supported by an unrestricted grant from the National Honey Board in the US) found it to be significantly superior to no treatment but no different to treatment with honey-flavoured dextromethorphan..$^{14}$ However, even honey may have adverse effects and is not recommended in children less than a year old because of the association with infant botulism. ${ }^{15}$ Lastly, it seems that there is likely to be a large placebo element associated with the taking of OTC cough medicines. ${ }^{16}$

At present there is incomplete evidence that OTC cough medicines provide effective symptomatic relief in children. Either we accept this and actively discourage the use of the more harmful agents, or we need to generate better evidence regarding the effectiveness and safety of OTC products. We also need to find out more about parental concerns and behaviour with regard to OTC cough medicines and the link between use of OTC cough medicines and subsequent antibiotic use, using both quantitative and qualitative approaches. In the meantime clinicians and pharmacists should be aware of the potential harms and misuses of these products in children of all ages, particularly those containing antihistamines, decongestants, or centrally acting agents.

\section{Susan M Smith,}

Senior Lecturer in Primary Care, Department of Public Health and Primary Care, Trinity College Centre for Health Sciences, The Adelaide and Meath Hospital Incorporating the National Children's Hospital, Dublin.

\section{Martin Henman,}

Senior Lecturer in Pharmacy Practice, Centre for the Practice of Pharmacy, The School of Pharmacy and Pharmaceutical Sciences, Trinity College Dublin.

\section{Knut Schroeder,}

Senior Clinical Lecturer, Academic Unit of Primary Health Care, University of Bristol, Bristol.

\section{Tom Fahey,}

Professor of General Practice, Department of General Practice, Royal College of Surgeons in Ireland, Dublin.

\section{REFERENCES}

1. NHS direct. About NHS direct. http://www.nhsdirect.nhs.uk/articles/article.aspx?arti cleId $=2046$ (accessed 6 Oct 2008).

2. Sharfstein JM, North M, Serwint JR. Over the counter but no longer under the radar - pediatric cough and cold medications. N Engl J Med 2007; 357(23): 2321-2324.

3. Morice AH, McGarvey L, Pavord I, on behalf of the British Thoracic Society Cough Guideline G. Recommendations for the management of cough in adults. Thorax 2006; 61(suppl 1): i1-24.

4. Anonymous. Sale of infant cough medicines splutters to a halt. Lancet 2008; 371: 1138.

5. BMJ Clinical Evidence. About us. http://clinicalevidence.bmj.com/ceweb/about/knowle dge.jsp (accessed 6 Oct 2008).

6. Naylor CD. Grey zones of clinical practice: some limits to evidence-based medicine. Lancet 1995 345(8953): 840-842.

7. Smith SM, Schroeder K, Fahey T. Over-the-counter medications for acute cough in children and adults in ambulatory settings. Cochrane Database Syst Rev 2008; (1): CD001381.

8. Schroeder K, Fahey T. Systematic review of randomised controlled trials of over the counter cough medicines for acute cough in adults. BMJ 2002; 324(7333): 329-331.

9. Sutcliffe AG, Wong ICK. Rational prescribing for children. BMJ 2006; 332(7556): 1464-1465.

10. Food and Drug Administration. Nonprescription Drug Advisory Committee Meeting. Cold, cough, allergy, bronchodilator, antiasthmatic drug products for over-the-counter human use.

http://www.fda.gov/ohrms/dockets/ac/07/briefing/20 07-4323b1-02-FDA.pdf (accessed 6 Oct 2008).

11. The baby website. Small talk: Calpol night. http://www.thebabywebsite.com/community/viewtop ic.php? $\mathrm{t}=5461$ \&start $=0 \&$ sid $=160$ (accessed 6 Oct 2008)

12. Medicines and Healthcare products Regulatory Agency. Updated advice - over-the-counter cough and cold medicines for young children.

http://www.mhra.gov.uk/NewsCentre/Pressreleases/C ON014446 (accessed 6 Oct 2008).

13. Hay AD, Wilson A, Fahey T, Peters TJ. The duration of acute cough in pre-school children presenting to primary care: a prospective cohort study. Fam Pract 2003; 20(6): 696-705.

14. Paul IM, Beiler J, McMonagle A, et al. Effect of honey, dextromethorphan, and no treatment on nocturnal cough and sleep quality for coughing children and their parents. Arch Pediatr Adolesc Med 2007; 161(12): $1140-1146$

15. Tanzi M, Gabay M. Association between honey consumption and infant botulism. Pharmacotherapy 2002; 22(11): 1479-1483.

16. Eccles R. Mechanisms of the placebo effect of sweet cough syrups. Respir Physiol Neurobiol 2006; 152(3): 340-348.

DOI: 10.3399/bjgp08X342642

\section{ADDRESS FOR CORRESPONDENCE}

\section{Susan M Smith}

Department of Public Health and Primary Care, Trinity College Centre for Health Sciences, AMNCH, Tallaght, Dublin 24, Ireland. E-mail: susmith@tcd.ie 